\title{
Development of primary malignant melanoma during treatment with a TNF- $\alpha$ antagonist for severe Crohn's disease: a case report and review of the hypothetical association between TNF- $\alpha$ blockers and cancer
}

This article was published in the following Dove Press journal:

Drug Design, Development and Therapy

26 March 2013

Number of times this article has been viewed

\author{
George Kouklakis' \\ Eleni I Efremidou ${ }^{2}$ \\ Michael Pitiakoudis ${ }^{3}$ \\ Nikolaos Liratzopoulos ${ }^{2}$ \\ Alexandros $\mathrm{Ch}$ \\ Polychronidis ${ }^{2}$ \\ 'Endoscopy Unit, ${ }^{2}$ First \\ Surgical Department, ${ }^{3}$ Second \\ Surgical Department, Medical \\ School, Democritus University \\ of Thrace, University Hospital of \\ Alexandroupolis, Alexandroupolis, \\ Greece
}

\begin{abstract}
It is recognized that immunosuppression may lead to reduced immune surveillance and tumor formation. Because of the immunosuppressive properties of tumor necrosis factor (TNF)-alpha (TNF- $\alpha$ ) antagonists, it is plausible that these biologics may increase the risk of the occurrence of malignancies or the reactivation of latent malignancies. TNF- $\alpha$ antagonists have gained momentum in the field of dermatology for treating rheumatoid arthritis and psoriasis, and they have revolutionized the treatment of other inflammatory autoimmune diseases such as refractory Crohn's disease. However, there is accumulating evidence that TNF- $\alpha$ inhibitors slightly increase the risk of cancer, including malignant melanoma (MM). The authors herein report the case of a 54-year-old female patient who developed a primary MM during treatment with adalimumab for severe Crohn's disease resistant to successive medical therapies. The patient had been receiving this TNF- $\alpha$ blocker therapy for 3 years before the occurrence of MM. After wide surgical excision of the lesion and staging (based on Breslow thickness and Clark level), evaluation with a whole-body computed tomography scan was negative for metastatic disease. The long duration of the adalimumab therapy and the patient's lack of a predisposition to skin cancer suggest an association between anti-TNF- $\alpha$ drugs and melanocytic proliferation. The authors also review the literature on the potential association between anti-TNF regimens and the occurrence of malignancies such as melanocytic proliferations. There is a substantial hypothetical link between anti-TNF- $\alpha$ regimens such as adalimumab and the potential for cancers such as melanoma. However, the risk of malignancy with biological therapy remains to be established, and most of the relevant studies have lacked the statistical power and randomization required for large clinical trials. Further long-term controlled clinical trials and registries are required to investigate this potentially serious association.
\end{abstract}

Keywords: adalimumab, tumor necrosis factor alpha, melanocytic proliferation, causal relationship

\section{Introduction}

Biologics, which represent new developments in genetic engineering and biotechnology, include T-cell modulators as well as tumor necrosis factor (TNF)-alpha (TNF- $\alpha$ ) antagonists (eg, etanercept, infliximab, and adalimumab [Humira ${ }^{\circledR}$ (D2E7); Abbott Laboratories, Abbott Park, IL, USA]). These bioengineered proteins target specific steps in the pathogenesis of severe immune-mediated disorders including psoriasis (PS), psoriatic arthritis, and rheumatoid arthritis (RA), and of several inflammatory 
autoimmune diseases such as Crohn's disease (CD). ${ }^{1-3}$ The resulting promise that $\mathrm{TNF}-\alpha$ antagonists have shown in the effective control of these inflammatory autoimmune diseases has revolutionized the treatment of these diseases. However, there is the potential for systemic toxicity with these therapies, related to the immunosuppressive effects, including serious infections and an increased risk of malignancy. ${ }^{3}$

The debate as to whether or not these systemic treatments increase a patient's risk of malignancy remains largely unresolved. Nevertheless, there has recently been considerable attention given to the growing evidence linking biological treatments with the occurrence of malignancies or the reactivation of latent malignancies, including malignant melanoma (MM). ${ }^{4-7}$ The issues concerning the long-term safety of biologics remain to be clarified.

Adalimumab is a fully human recombinant immunoglobulin G1 (IgG1) monoclonal cytokine of the innate immune system that plays a key role in the surveillance of malignancies and the response to infections. ${ }^{8}$ The authors herein report the case of a patient who developed a primary MM after treatment with adalimumab for severe refractory CD.

\section{Case report}

A 54-year-old woman of European Caucasian ethnicity and Greek nationality and suffering from severe CD presented at the surgical department of the University Hospital of Alexandroupolis, Greece, in February 2011 with an asymptomatic pigmented skin lesion just above the sternum. The lesion was $0.7 \mathrm{~cm}$ in diameter, with an irregular border and dark color variegation. The patient reported that she had a nevus at this site that had changed color and size during the previous year. She recalled this nevus being present in childhood and that it had a well-defined border and coloration. There were no risk factors for MM such as nevus phenotypic risk factors - the patient had brown hair and eyes, she did not have freckling on the face as a child, she was able to tan easily and deeply, and she was resistant to burning. There was no high total nevus count on the body surface, no history of high environmental ultraviolet radiation exposure, and no personal or family history of MM or any dysplastic nevus syndrome.

The patient's medical history included severe ileal CD (involving approximately $35 \mathrm{~cm}$ of terminal ileum) that was resistant to successive medical therapies. She had suffered from $\mathrm{CD}$ for the previous 8 years and had been treated with adalimumab (40 mg subcutaneously every other week) for the previous 3 years. After the biological treatment, remission of active $\mathrm{CD}$ was achieved and no adverse events were observed. The patient was one of a total of 78 patients with severe CD treated with an anti-TNF regimen (47 of these patients were receiving adalimumab) at this time in the Inflammatory Bowel Diseases Unit in the University Hospital of Alexandroupolis.

The skin lesion was excised and histology of the biopsy specimen showed a MM (Breslow thickness of $1 \mathrm{~mm}$, Clark level III), potentially arising on a preexisting nevus. Adalimumab was discontinued and the patient was treated with budesonide (Budenofalk ${ }^{\circledR}$; Galenica, Athens, Greece) (enteric-coated capsules $3 \mathrm{mg}$ ) $9 \mathrm{mg}$ daily for 8 weeks, following consultation with a gastroenterologist. A wider excision of the lesion, with a $2.5 \mathrm{~cm}$ margin, was performed and this was followed by a bilateral axillary lymph node biopsy. The bilateral axillary node biopsy samples were negative for melanoma. The patient subsequently underwent a wholebody computed tomography scan, which was negative for metastatic disease. The results of laboratory investigations were within normal ranges. The patient received no other treatment for MM and was monitored closely.

The clinical examination and the laboratory and imaging investigations performed at the 3- and 6-month follow-up appointments were negative for disease recurrence or metastatic foci. However, the patient presented with a relapse of CD with bowel obstruction within the 2-month period of receiving budesonide therapy; surgical treatment was proposed and discussed in an oncologic multidisciplinary team meeting held at University Hospital of Alexandroupolis, Greece. An uncomplicated right hemicolectomy with anastomosis of the proximal ileum and transverse colon was performed in September 2011.

The oncologic multidisciplinary team did not approve postoperative treatment with azathioprine, which was the proposed by gastroenterologist for $\mathrm{CD}$, and therefore the patient received no medical treatment after the surgery. The patient is currently in remission for $\mathrm{CD}$. A total colonoscopy performed in December 2011 and again in July 2012 revealed no sign of active $\mathrm{CD}$ and the patient remains closely monitored.

\section{Discussion}

The literature includes several reports examining the carcinogenic risk linked to biologic therapy. Most of these nonrandomized studies concern PS and RA patients, including children, who developed hematologic malignancies, nonmelanoma skin cancer (NMSC), or melanoma after treatment with TNF blockers. ${ }^{1-4}$

TNF- $\alpha$ is a cytokine of the innate immune system that is critical in the surveillance of malignancies and infection. TNF- $\alpha$ antagonists specifically bind to both the soluble and 
the transmembrane forms of TNF- $\alpha$ and include infliximab, etanercept, and adalimumab. Currently the main indications of these TNF- $\alpha$ antagonists remain RA, PS, psoriatic arthritis, and $C D$. The adverse events are relatively mild, while serious infections such as tuberculosis, malignancies, and neurological disorders may complicate the therapy with biologic agents. ${ }^{1-3,9}$ TNF- $\alpha$ antagonists have been shown to reactivate latent tuberculosis, which in most cases occurs within the first 90 days after therapy has commenced..$^{10,11}$

Although evidence for the promotion of tumorigenesis with biologics is still vague, and although the relevant studies reported in the literature lack the statistical power required for large clinical trials and long-term follow-up investigational periods, there have been various case reports that give support to the logical hypothesis that TNF- $\alpha$ inhibitors can permit malignancies to occur. ${ }^{2,3,12,13}$

While the mechanism underlying the action of TNF- $\alpha$ antagonists has been summarized in the dermatological literature, long-term studies concerning the malignancy risks associated with these agents have been more extensively explored in the RA population. ${ }^{3}$ For instance, a systematic review and meta-analysis of nine randomized controlled trials that assessed the adverse events with infliximab and adalimumab in patients with RA suggested the presence of increased risks of malignancies and severe infections. ${ }^{12,14}$ However, other investigators do not agree there is an association. ${ }^{15}$

Furthermore, few of the reports involving patients with RA have concluded that there is an increased risk of NMSC and reactivation of latent malignancies (eg, elanoma) in patients receiving TNF- $\alpha$ antagonists. ${ }^{1,3,16-21}$ Whether the findings extracted from RA studies translate to an increased risk in patients suffering from PS is still a matter of debate. ${ }^{3}$ Studies on PS in the literature exploring the risk of cancer associated with TNF- $\alpha$ antagonists similarly lack the statistical power required for large clinical trials. It has also become clear that PS itself places patients at risk of malignancy. ${ }^{3}$ However, there are several case reports that support the theory that anti-TNF- $\alpha$ therapy can induce or reactivate latent malignancies. ${ }^{2,17,22-25}$ Furthermore, most studies examining the carcinogenic risk of TNF- $\alpha$ inhibitors suggest that TNF- $\alpha$ inhibitors can slightly increase the risk of cancer, including NMSC and hematologic malignancies. ${ }^{3}$

The relationship between lymphoma and TNF-blockers has also been documented in a few case reports of PS patients. ${ }^{26}$ Girard et $\mathrm{a}^{26}$ reported a case of a patient with long-standing PS who was diagnosed with a lymphoma after initiation of a TNF- $\alpha$ blocker. In 2007, Fulchiero et $\mathrm{al}^{2}$ first reported the late recurrence of eruptive locoregional metastatic melanoma in two patients after initiation of TNF- $\alpha$ antagonists for PS in one of the patients and RA in the other.

The association between lymphoproliferative disorders and T-cell modulators has been studied mostly in the RA and $\mathrm{CD}$ populations. Infliximab and adalimumab are both therapeutic options for refractory CD. It is well known that inflammation in $\mathrm{CD}$ is associated with high levels of tissue TNF- $\alpha$ expression, and therapies directed against this cytokine have recently become the focus of interest. Infliximab, a chimeric ( $75 \%$ human and $25 \%$ murine protein) IgG1 monoclonal antibody against TNF- $\alpha$, is the prototype anti-TNF- $\alpha$ agent. Shown to be effective for both induction and maintenance of fistula closure in approximately twothirds of patients, infliximab has now become the cornerstone in medical therapy for fistulizing CD. However, some patients with fistulizing CD are resistant or intolerant to infliximab. Recently, adalimumab, a fully human, subcutaneously delivered IgG1 monoclonal antibody that binds with high affinity and specificity to TNF but not to lymphotoxin, has been proved to be a safe and effective treatment for induction and maintenance of remission in adult patients with moderate to severe CD (luminal and/or fistulizing) who are resistant to conventional therapy or intolerant to infliximab. ${ }^{27}$

Debate on the association between the risk of lymphoma and TNF- $\alpha$ antagonist therapy continues. Diak et $\mathrm{al}^{9}$ reported cases of nongastrointestinal malignancies in children with juvenile idiopathic arthritis and inflammatory bowel disease treated with TNF- $\alpha$ blockers, with only one case of MM that developed in a 14-year-old child with CD receiving infliximab. ${ }^{9}$ Although it was concluded that therapy with TNF- $\alpha$ blockers in children might be associated with the development of malignancy, a clear causal relationship was not established.

Several studies have found an increased incidence of NMSC in patients with RA. ${ }^{16,21}$ Furthermore, the development of multiple keratoacanthomas and squamous cell carcinomas has also been reported in patients with RA and PS after the initiation of etanercept or infliximab therapy. ${ }^{17,19}$ Also, it is well established that quiescent or previously treated melanoma can be reactivated by immunosuppressive therapy after solid organ transplantation. ${ }^{18,28}$

However, a causal relationship between TNF- $\alpha$ inhibitors and the development and progression or the reactivation of MM has not yet been described. The authors are aware of few reports in the literature of an association between MM and TNF- $\alpha$ blockers. Fulchiero et $\mathrm{al}^{2}$ reported two cases of reactivated $\mathrm{MM}$ in patients treated with etanercept for PS and adalimumab for RA. Gordon et $\mathrm{al}^{29}$ reported a case 
of primary $\mathrm{MM}$ in a patient receiving adalimumab for PS. Kowalzick et $\mathrm{al}^{30}$ reported the occurrence of $\mathrm{MM}$ in a patient treated consecutively with infliximab, adalimumab, and etanercept for PS. Khan et $\mathrm{al}^{31}$ reported another case of primary $\mathrm{MM}$ in a patient treated with infliximab for RA. Finally, Katoulis et $\mathrm{al}^{1}$ reported the development of two primary MMs after treatment with adalimumab in a patient with RA.

To the best of the present authors' knowledge, this is the first reported case of primary MM occurring after treatment with a TNF- $\alpha$ blocker (adalimumab) in an adult patient with CD. Despite the controversial role of TNF- $\alpha$ inhibition in the development of MM, there is strong evidence that the initiation of TNF- $\alpha$ blockers in the treatment and control of any serious autoimmune condition potentially causes an increased risk for skin and other malignancies. ${ }^{32,33}$ Therefore, patients receiving immunosuppressive therapy should be closely monitored, with follow-ups including skin examinations.

\section{Conclusion}

In conclusion, therapy with TNF- $\alpha$ blockers may be associated with the development of malignancies or the malignant transformation of benign lesions. Although the risk seems low and is therefore difficult to uncover in clinical trials, clinicians must weigh the possibility of malignancy against the severity of the underlying disease. Moreover, biologics are contraindicated in patients with confirmed malignancy or premalignancy states. Further long-term controlled clinical trials and registries are required to investigate this potentially serious association.

\section{Disclosure}

The authors report no conflicts of interest in this work.

\section{References}

1. Katoulis AC, Kanelleas A, Zambacos G, Panayiotides I, Stavrianeas NG. Development of two primary malignant melanomas after treatment with adalimumab: a case report and review of the possible link between biological therapy with TNF-alpha antagonists and melanocytic proliferation. Dermatology. 2010;221(1):9-12.

2. Fulchiero GJ Jr, Salvaggio H, Drabick JJ, et al. Eruptive latent metastatic melanomas after initiation of antitumor necrosis factor therapies. $\mathrm{J} \mathrm{Am}$ Acad Dermatol. 2007;56(Suppl 5):S65-S67.

3. Patel RV, Clark LN, Lebwohl M, Weinberg JM. Treatments for psoriasis and the risk of malignancy. J Am Acad Dermatol. 2009;60(6): 1001-1017.

4. Krueger JG, Bowcock A. Psoriasis pathophysiology: current concepts of pathogenesis. Ann Rheum Dis. 2005;64(Suppl 2):ii30-ii36.

5. Mahmoud F, Abdul H, al Saleh Q, et al. Elevated B-lymphocyte levels in lesional tissue of non-arthritic psoriasis. J Dermatol. 1999;26(7): 428-433.

6. Müller KM, Röcken M, Joel D, Bonnefoy JY, Saurat JH, Hauser C. Mononuclear cell-bound CD23 is elevated in both atopic dermatitis and psoriasis. J Dermatol Sci. 1991;2(2):125-133.
7. Naldi L. Malignancy concerns with psoriasis treatments using phototherapy, methotrexate, cyclosporine, and biologics: facts and controversies. Clin Dermatol. 2010;28(1):88-92.

8. Mease PJ.Adalimumab: an anti-TNF agent for the treatment of psoriatic arthritis. Expert Opin Biol Ther. 2005;5(11):1491-1504.

9. Diak P, Siegel J, La Grenade L, Choi L, Lemery S, McMahon A. Tumor necrosis factor alpha blockers and malignancy in children: forty-eight cases reported to the Food and Drug Administration. Arthritis Rheum. 2010;62(8):2517-2524.

10. Ehlers S, Hölscher C, Scheu S, et al. The lymphotoxin beta receptor is critically involved in controlling infections with the intracellular pathogens Mycobacterium tuberculosis and Listeria monocytogenes. J Immunol. 2003;170(10):5210-5218.

11. Wallis RS, Broder MS, Wong JY, Hanson ME, Beehouwer DO. Granulomatous infectious diseases associated with tumor necrosis factor antagonists. Clin Infect Dis. 2004;38(9):1261-1265.

12. Bongartz T, Sutton AJ, Sweeting MJ, Buchan I, Matteson EL, Montori V. Anti-TNF antibody therapy in rheumatoid arthritis and the risk of serious infections and malignancies: systematic review and metaanalysis of rare harmful effects in randomized controlled trials. JAMA. 2006;295(19):2275-2285.

13. Stone JH, Holbrook JT, Marriott MA, et al; Wegener's Granulomatosis Etanercept Trial Research Group. Solid malignancies among patients in the Wegener's Granulomatosis Etanercept Trial. Arthritis Rheum. 2006;54(5):1608-1618.

14. Brown SL, Greene MH, Gershon SK, Edwards ET, Braun MM. Tumor necrosis factor antagonist therapy and lymphoma development: twentysix cases reported to the Food and Drug Administration. Arthritis Rheum. 2002;46(12):3151-3158.

15. Askling J, Fored CM, Baecklund E, et al. Haematopoietic malignancies in rheumatoid arthritis: lymphoma risk and characteristics after exposure to tumor necrosis factor antagonists. Ann Rheum Dis. 2005;64(10): 1414-1420.

16. Chakravarty EF, Michaud K, Wolfe F. Skin cancer, rheumatoid arthritis, and tumor necrosis factor inhibitors. J Rheumatol. 2005;32(11): 2130-2135.

17. Fryrear RS 2nd, Wiggins AK, Sangueza O, Yosipovitch G. Rapid onset of cutaneous squamous cell carcinoma of the penis in a patient with psoriasis on etanercept therapy. J Am Acad Dermatol. 2004;51(6):1026.

18. Euvrard S, Kanitakis J, Claudy A. Skin cancers after organ transplantation. N Engl J Med. 2003;348(17):1681-1691.

19. Smith KJ, Skelton HG. Rapid onset of cutaneous squamous cell carcinoma in patients with rheumatoid arthritis after starting tumor necrosis factor alpha receptor IgG1-Fc fusion complex therapy. $J \mathrm{Am}$ Acad Dermatol. 2001;45(6):953-956.

20. Esser AC, Abril A, Fayne S, Doyle JA. Acute development of multiple keratoacanthomas and squamous cell carcinomas after treatment with infliximab. J Am Acad Dermatol. 2004;50(Suppl 5):S75-S77.

21. Askling J, Fored CM, Brandt L, et al. Risks of solid cancers in patients with rheumatoid arthritis and after treatment with tumor necrosis factor antagonists. Ann Rheum Dis. 2005;64(10):1421-1426.

22. Ly L, Czarnecki D. The rapid onset of multiple squamous cell carcinomas during etanercept treatment for psoriasis. Br J Dermatol. 2007; 157(5):1076-1078.

23. Nair B, Raval G, Mehta P. TNF-alpha inhibitor etanercept and hematologic malignancies: report of a case and review of the literature. $\mathrm{Am}$ J Hematol. 2007;82(11):1022-1024.

24. Hurley MY, George MN, Leonardi CL, Frater JL. A transient benign lymph node-based proliferation of T-cells stimulating non-Hodgkin lymphoma in a patient with psoriasis treated with tumor necrosis factor alpha and CD11a antagonists. Diagn Pathol. 2008;3:13-18.

25. Tyring S, Gordon KB, Poulin Y, et al. Long-term safety and efficacy of $50 \mathrm{mg}$ of etanercept twice weekly in patients with psoriasis. Arch Dermatol. 2007;143(6):719-726.

26. Girard C, Guillot B, Bessis D. Gastric MALT lymphoma in a patient receiving infliximab for psoriasis. Br J Dermatol. 2008;159(2): 497-498. 
27. Kouklakis G, Efremidou EI, Zezos P, et al. Adalimumab: an effective and promising treatment for patients with fistulizing Crohn's disease: a case series. J Med Case Rep. 2011;5:109.

28. Penn I. Malignant melanoma in organ allograft recipients. Transplantation. 1996;61(2):274-278.

29. Gordon KB, Langley RG, Leonardi C, et al. Clinical response to adalimumab treatment in patients with moderate to severe psoriasis: double-blind, randomized controlled trial and open-label extension study. J Am Acad Dermatol. 2006;55(4):598-606.

30. Kowalzick L, Eickenscheidt L, Komar M, Schaarschmidt E. Long term treatment of psoriasis with TNF-alpha antagonists: occurrence of malignant melanoma. Hautarzt. 2009;60(8):655-657. German [with English abstract].
31. Khan I, Rahman L, McKenna DB. Primary cutaneous melanoma: a complication of infliximab treatment? Clin Exp Dermatol. 2009;34(4) 524-526.

32. Seminerio JL, Loftus EV Jr, Colombel JF, Thapa P, Sandborn WJ. Infliximab for Crohn's disease: the first 500 patients followed up through 2009. Dig Dis Sci. Epub September 29, 2012.

33. Burmester GR, Panaccione R, Gordon KB, McIlraith MJ, Lacerda AP Adalimumab: long-term safety in 23458 patients from global clinical trials in rheumatoid arthritis, juvenile idiopathic arthritis, ankylosing spondylitis, psoriatic arthritis, psoriasis and Crohn's disease. Ann Rheum Dis. Epub July 6, 2012.

\section{Publish your work in this journal}

Drug Design, Development and Therapy is an international, peerreviewed open-access journal that spans the spectrum of drug design and development through to clinical applications. Clinical outcomes, patient safety, and programs for the development and effective, safe, and sustained use of medicines are a feature of the journal, which has also been accepted for indexing on PubMed Central. The manuscript management system is completely online and includes a very quick and fair peer-review system, which is all easy to use. Visit http://www.dovepress.com/testimonials.php to read real quotes from published authors.

Submit your manuscript here: http://www.dovepress.com/drug-design-development-and-therapy-journal 